\title{
O.S.P.
}

L'orientation scolaire et professionnelle

$30 / 3 \mid 2001$

Juger et être jugé : perspectives psychosociales

\section{S. Paugam. Le salarié de la précarité.}

Paris : PUF.

Véronique Vergnereau

\section{(2) OpenEdition}

Journals

Édition électronique

URL : http://journals.openedition.org/osp/5170

DOI : 10.4000/osp.5170

ISSN : 2104-3795

Éditeur

Institut national d'étude du travail et d'orientation professionnelle (INETOP)

Référence électronique

Véronique Vergnereau, «S. Paugam. Le salarié de la précarité. », L'orientation scolaire et professionnelle [En ligne], 30/3 | 2001, mis en ligne le 20 juillet 2016, consulté le 16 décembre 2020. URL : http:// journals.openedition.org/osp/5170 ; DOI : https://doi.org/10.4000/osp.5170

Ce document a été généré automatiquement le 16 décembre 2020.

(C) Tous droits réservés 


\title{
S. Paugam. Le salarié de la précarité.
}

Paris : PUF.

\author{
Véronique Vergnereau
}

\section{RÉFÉRENCE}

Paris : PUF.

1 Serge Paugam, Directeur de recherche au C.N.R.S. et membre de l'observatoire National de la Pauvreté et de l'Exclusion sociale, analyse dans son dernier ouvrage les incidences de la précarité professionnelle sur la sphère privée et professionnelle.

2 Depuis les années 1970/80, on assiste à une véritable "explosion du travail précaire » qui touche désormais des franges nombreuses de la population, mais atteint principalement les femmes, les jeunes et les publics les moins qualifiés. Cette situation n'est pas seulement la conséquence d'une conjoncture de crise. Elle a aussi pour origine la volonté des entreprises d'augmenter la flexibilité de la main-d'oeuvre d'une part, associée aux mesures politiques visant à diminuer les chiffres du chômage, d'autre part.

3 Serge Paugam analyse la précarité professionnelle aussi bien à partir du rapport au travail qu'à partir du rapport à l'emploi. Le rapport au travail permet d'appréhender les dimensions de la satisfaction ou de l'insatisfaction des salariés dans l'exercice de leur fonction. Les salariés précaires éprouvent peu ou pas de satisfaction dans l'entreprise.

4 L'analyse du rapport à l'emploi permet, elle, de distinguer le degré de stabilité de la situation professionnelle des salariés. Cette stabilité se définit par la nature du contrat de travail, mais aussi par la politique économique de l'entreprise, selon qu'elle envisage ou pas de licenciements. Les salariés précaires sont ceux qui se trouvent dans des « formes périphériques d'emploi " (C.D.D., intérim, temps partiel, contractuels, apprentissage, etc.) et ceux dont le C.D.I. n'est pas pérenne.

5 Le rapport à l'emploi et le rapport au travail sont deux dimensions de l'intégration professionnelle. Paugam distingue quatre formes d'intégrations : l'intégration assurée 
(satisfaction au travail et stabilité dans l'emploi), l'intégration incertaine (satisfaction dans le travail et instabilité dans l'emploi), l'intégration laborieuse (insatisfaction dans le travail et stabilité dans l'emploi) et enfin l'intégration disqualifiante (insatisfaction dans le travail et instabilité dans l'emploi) qui correspond à la forme la plus prononcée de la précarité professionnelle.

6 Ces différentes formes d'intégration professionnelle ont des conséquences diverses sur les salariés, notamment au sein de la famille (relation parentale, de couple), au sein de la vie de l'entreprise et des syndicats (faible mobilisation, voire distanciation) et dans leurs rapports à la politique.

7 En résumé, Paugam nous montre comment, dans le monde du travail, on trouve des situations de précarité telles qu'elles peuvent être comparées à des situations de chômage : les unes et les autres produisent des « crises identitaires » très similaires. Le processus de " disqualification sociale " qu'elles mettent en jeu se traduit par une attitude de retrait vis-à-vis de la vie collective principalement pour les salariés proches de l'intégration disqualifiante, mais également pour les salariés proches de l'intégration incertaine et laborieuse. 